\title{
Canadians call for better palliative care
}

$\mathrm{C}$

anadians share a strong desire for better palliative care, regardless of where they stand on physician-assisted death, a national consultation by the Canadian Medical Association (CMA) reveals.

At 11 CMA-sponsored town hall meetings plus a live chat held across Canada this year, CMA members and the public expressed almost universal agreement on the importance of advanced-care directives and the need for a national strategy to improve palliative care. Over 1500 people participated.

"We shouldn't be distracted from the real thing that needs to be done right now," said CMA President, Dr. Louis Hugo Francescutti at a media conference June 10. "Patients are telling us they don't want to die in pain, they don't want to die alone, and they don't want to be a burden to their family, and palliative care goes an enormously long way to addressing those issues."

According to Francescutti, "it's crystal clear that Canadians want to have some degree of control at end-of-life," in some cases through physicianassisted death. But the overwhelming consensus is an "expectation that every Canadian will have access to good palliative care."

Currently, only $15 \%-30 \%$ of Canadians, depending on where they live, are afforded that opportunity.

In a report on the consultation released June 10, CMA also concludes that medical students, residents and practising physicians need more training to deliver good palliative care.

"Every medical student has to deliver a baby because we know that's a part of life," says Francescutti. "Last time I checked, death was a part of life, and yet medical schools really don't do a good job training people on this issue."

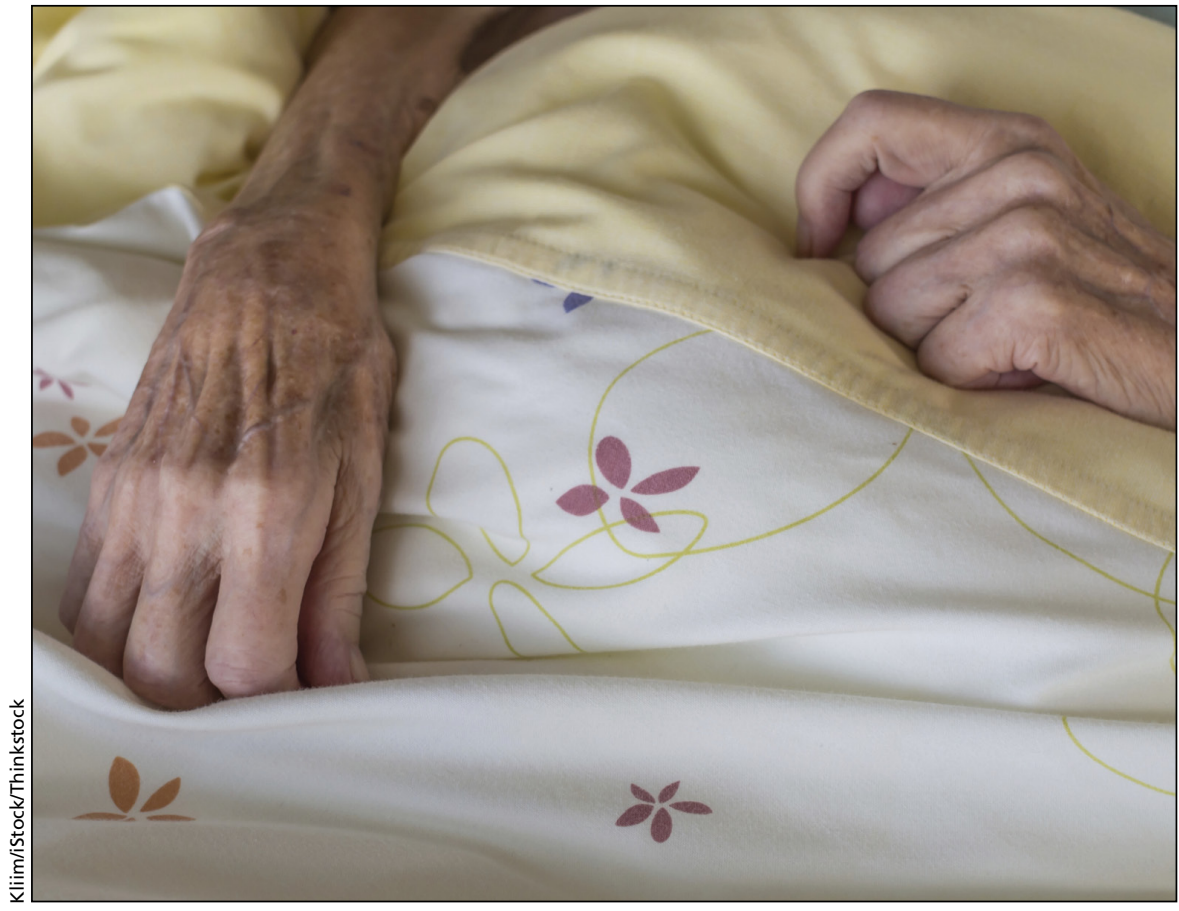

Canada must do better to provide citizens a "good death," a national consultation found.

Further, should Canada change laws to allow physician-assisted death, strict protocols and safeguards are required to protect vulnerable individuals and populations, the report states.

CMA's stance on the issue remains clear, says Francescutti. Physician-assisted suicide "is illegal and we're going to follow the law."

However, he notes, "the profession is prepared to discuss this in greater detail and what we heard from the public is they're expecting our [federal] government to have this conversation as well."

In the meantime, Francescutti cautions Quebec physicians to "tread very gently." Quebec became the first Canadian province to legalize medically assisted death, when it passed Bill 52, an Act respecting end-of-life care, on June 5.

"We're hearing from the premier of
Quebec that they've instructed Crown prosecutors not to prosecute any physicians [under the new law allowing medical aid in dying], but on the other hand we hear from the federal government that the minister of justice is reviewing this and will act accordingly."

Some medical institutions, such as the West Island Palliative Care Residence in Kirkland, Que., have already declared they will not be providing physician-assisted death under the new law.

According to a recent statement, "the Residence will continue to act in the way it always has - to provide the best possible care and comfort, including symptom relief to the dying but without taking any actions that hasten the natural process of death." - Lauren Vogel, CMAJ

CMAJ 2014. DOI:10.1503/cmaj.109-4831 